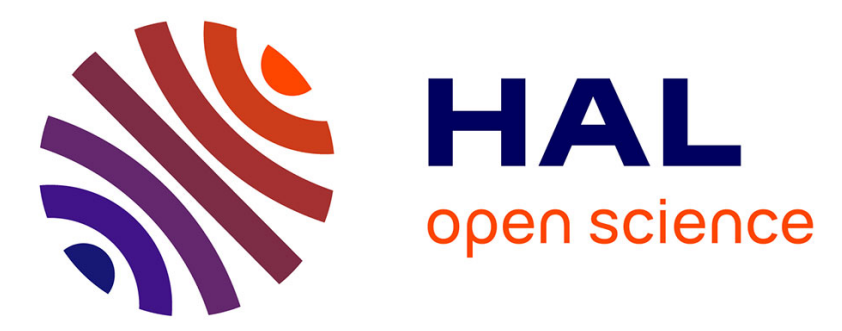

\title{
Childhood trauma, dimensions of psychopathology and the clinical expression of bipolar disorders: A pathway analysis
}

B. Etain, M. Lajnef, C. Henry, V. Aubin, J. M. Azorin, Frank Bellivier, T. Bougerol, P. Courtet, S. Gard, J. P. Kahn, et al.

\section{To cite this version:}

B. Etain, M. Lajnef, C. Henry, V. Aubin, J. M. Azorin, et al.. Childhood trauma, dimensions of psychopathology and the clinical expression of bipolar disorders: A pathway analysis. Journal of Psychiatric Research, 2017, 95, pp.37-45. 10.1016/j.jpsychires.2017.07.013 . hal-01760382

\section{HAL Id: hal-01760382 https://hal.science/hal-01760382}

Submitted on 9 Jan 2019

HAL is a multi-disciplinary open access archive for the deposit and dissemination of scientific research documents, whether they are published or not. The documents may come from teaching and research institutions in France or abroad, or from public or private research centers.
L'archive ouverte pluridisciplinaire HAL, est destinée au dépôt et à la diffusion de documents scientifiques de niveau recherche, publiés ou non, émanant des établissements d'enseignement et de recherche français ou étrangers, des laboratoires publics ou privés. 


\title{
Childhood trauma, dimensions of psychopathology and the clinical expression of bipolar disorders: A pathway analysis
}

\author{
B. Etain a, b, c, d, ${ }^{*}$, M. Lajnef e, C. Henry d, e, f, g, h, V. Aubin d, i, J.M. Azorin d, j,k,

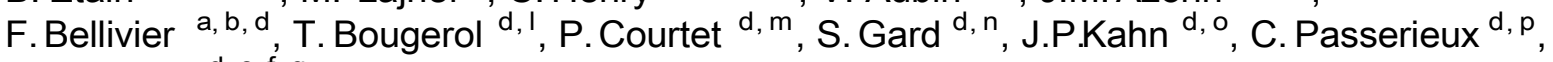 \\ M. Leboyer d, e, f, g, FACE-BD Clinical Coordinating Center (FondaMental Foundation), \\ FACE-BD Data Coordinating Center (FondaMental Foundation), FACE-BD Clinical Sites and \\ Principal Collaborators in France
}

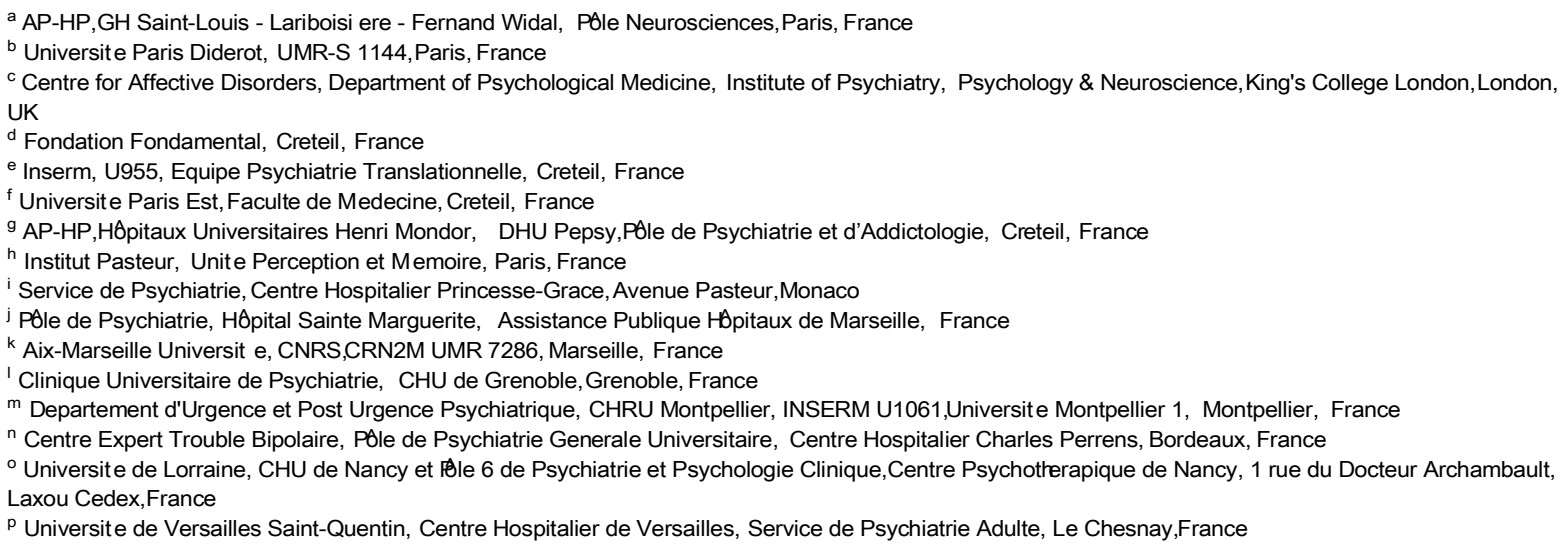

abstract

Keywords:

Bipolar disorder Childhood trauma Sexual abuse Emotional abuse Affect instability Lability impulsivity Hostility

Suicide

Substance misuse

Rapid cycling

Age at onset

Polarity at onset

Results: The path-analysis demonstrated significant associations between emotional abuse and all the affective/impulsive dimensions $(p<0.001)$. Sexual abuse was moderately associated with emotionrelated dimensions but not with impulsivity nor motor hostility. In turn, affect intensity and attitudinal hostility were associated with high risk for lifetime presence of suicide attempts $(p<0.001)$, whereas impulsivity was associated with a higher risk of lifetime presence of substance misuse $(p<0.001)$. No major additional paths were identified when including Emotional and Physical Neglect in the model.

Conclusions: This study provides refinement of the links between early adversity, dimensions of psychopathology and the complexity/severity of BD. Mainly, dimensions of affective dysregulation,

\footnotetext{
* Corresponding author. Departement de Psychiatrie et de M edecine Addictologigue, Centres Experts Bipolaire et Dépression Résistante, HØpital Fernand Widal, 200, rue du Faubourg Saint-Denis, 75475 Paris Cedex 10, France.

E-mail addresses: bruno.etain@inserm.fr, bruno.etain@kcl.ac.uk (B. Etain).
} 


\section{Introduction}

A substantial body of literature indicates that childhood traumatic events influence the complexity/severity of the clinical expression of bipolar disorders (BD) (Aas et al., 2016a). Early reviews have suggested that childhood trauma was associated with several indicators of worse course and prognosis of BD such as an earlier age at onset, suicide attempts, psychotic features, rapid cycling, substance use disorders or a higher frequency of mood recurrences (Daruy-Filho et al., 2011; Etain et al., 2008; Fisher and Hosang, 2010). More recent studies in this field have replicated many of these findings. For example, in a large sample of patients with $\mathrm{BD}$, we have demonstrated an association between emotional and sexual abuse (but not physical abuse), an earlier age at onset, rapid cycling, suicidal attempt and substance use disorders (Etain et al., 2013a). Other studies further demonstrated associations between childhood trauma and age at onset (Aas et al., 2013; Anand et al., 2015; Li et al., 2014; Post et al., 2015, 2016), delusions or hallucinations (Cakir et al., 2016; Upthegrove et al., 2015), suicide attempts (Erten et al., 2014; Janiri et al., 2014), a deteriorating illness course (Post et al., 2015), comorbid panic disorder (Pavlova et al., 2016) or rapid cycling (Watson et al., 2013). Recently, data coming from 30 studies were combined in a meta-analysis that confirmed association between childhood trauma and greater mania, depressive and psychosis severity, higher risk of comorbidity with post-traumatic stress, anxiety and substance misuse disorders, earlier age of $\mathrm{BD}$, higher risk of rapid cycling and suicide attempt (Agnew-Blais and Danese, 2016).

The literature regarding childhood trauma and BD has suggested that not all subtypes of trauma had equivalent clinical consequences (Aas et al., 2016a). Emotional, physical and sexual abuse often co-occur and are highly inter-related, so their respective contribution to different phenotypes may be uneasy to disentangle. Previous studies have shown a main effect of emotional and sexual abuse on clinical complexity/severity (Etain et al., 2013a; Janiri et al., 2014; Maniglio, 2013; Post et al., 2014; Watson et al., 2013). Physical abuse might have a weaker influence on the global complexity/severity while a more specific effect on psychotic features (Etain et al., 2017; Upthegrove et al., 2015). However, other studies found no effect of physical abuse on psychotic features in BD after covariations with emotional and sexual abuse (Etain et al., 2013a). A systematic review suggested that sexual abuse was strongly (and perhaps directly) associated with post-traumatic stress disorder in BD; whereas it was less strongly (and perhaps indirectly) related to suicide attempts, alcohol and/or drug abuse or dependence, psychotic symptoms, and an early age of illness onset (Maniglio, 2013). Disentangling the respective contribution of each type of childhood abuse as risk factors for complexity/severity of BD is of potential clinical interest but a challenge.

Childhood trauma might influence not only on categorical indicators of complexity/severity but also on various dimensions of psychopathology that are linked to such a complexity/severity of the disorder. In patients with BD, higher levels of trauma correlated with a higher emotional deregulation such as increased affective lability and affect intensity (Aas et al., 2014a; Etain et al., 2008). Childhood trauma has also been associated with traits of aggression in BD (Garno et al., 2008), suggesting that childhood trauma might influence not only emotional regulation but also components of hostility or impulsivity. In turn, such measures of emotional, behavioral and impulsive dysregulation have been proposed to be associated to the clinical complexity/severity of BD. Studies that used self-reported questionnaires described that higher levels of both affect intensity and affective lability in normothymic patients with BD were associated with lifetime comorbidities (substance misuse, social phobia), an earlier age at onset and suicide attempts (Henry et al., 2007; Mathieu et al., 2014; Olie et al., 2015). In patients with $\mathrm{BD}$, impulsivity has also been associated with alcohol or cannabis misuse comorbidity, rapid cycling and mixed episodes (Etain et al., 2013b), but not with suicidality when using assessments such as the Barrat Impulsivity Scale (Etain et al., 2013b; Olie et al., 2015; Parmentier et al., 2012; Patton et al., 1995). Finally, externalized or internalized hostility and aggression traits were associated with suicide attempts in BD (Galfalvy et al., 2006; Garno et al., 2008; Parmentier et al., 2012).

Although not exhaustively reviewed here, these findings highlight the hypothesis of a pathway from childhood trauma, through dimensions of psychopathology to clinical indicators of the complexity/severity or course of BD. Some authors have proposed to investigate whether some dimensions (in that case affective instability) mediate the association between childhood traumatic events and outcomes of BD (Marwaha et al., 2016) and suggest testing this hypothesis using formal path analytic statistical techniques. Our aim was therefore to use a path analysis to model the links from emotional, physical and sexual abuse to indicators of complexity/severity of BD through dimensions of emotional deregulation and impulsivity/hostility in a sample of patients with $\mathrm{BD}$ who have been assessed during remission.

\section{Material and methods}

\subsection{Sample}

Previous publications using the FACE-BD sample described in details the data collection (Boudebesse et al., 2013; Godin et al., 2014; Henry et al., 2011). Briefly, the sample was collected from outpatients who were assessed in nine psychiatric departments belonging to the French network of centers of expertise in bipolar disorders. This network was established by the French Ministry of Research,developed under the aegis of the Fondamental Foundation and afterward funded by the French Ministry of Health. The network provides support to general practitioners and psychiatrists requiring assistance in the diagnosis and management of patients with BD.

All outpatients 18 years or older assessed in the expert centers and diagnosed with BD according to DSM-IV criteria (types I, II, and not otherwise specified) (American Psychiatric Association, 1994) can be enrolled in the Fondamental Advanced Centers of Expertise in Bipolar Disorders (FACE-BD) cohort.

The institutional review board (Comit e de Protection des Personnes lle de France IX; January 18, 2010) approved the assessment protocol in accordance with the French laws for non-interventional studies. The institutional review board asked us to provide all patients with an informational letter. Written formal consent was not required, but we sought the agreement of the patient in each case 
before analyzing the clinical data. The authors assert that all procedures contributing to this work comply with the ethical standards of the relevant national and institutional committees on human experimentation and with the Helsinki Declaration of 1975, as revised in 2008 .

\subsection{Clinical assessment}

The patients were interviewed by senior psychiatrists or psychologists specialized in BD. The Structured Clinical Interview for DSM-IV Axis I Disorders (First et al., 1995) was used to confirm the diagnosis of BD and to assess the lifetime history of mood episodes, course and comorbid psychiatric disorders according to DSM-IV-TR (American Psychiatric Association, 1994). Current mood state and residual depressive and manic symptoms were assessed with the Montgomery Asberg Depression Rating and the Young Mania Rating Scale (Montgomery and Asberg, 1979; Young et al., 1978). Patients selected for this analysis had MADRS and YMRS scores below 8 and were at least at three months of the end of their last mood episode.

All the clinical indicators of complexity, severity or poor outcome in BD were derived from the information retrospectively collected using the SCID. For this study, we have selected five variables: age at onset, polarity at onset, suicide attempt, rapid cycling, and substance misuse disorder. Age at onset was defined as the age at which the first mood episode occurred (depressive, manic, hypomanic, or mixed according to DSM-IV criteria). Two types of onset polarity were defined: a depressive onset (for which the first mood episode met DSM-IV criteria for a major depressive episode) and a manic onset (for which the first mood episode met DSM-IV criteria for a manic, hypomanic, or mixed episode). Suicide attempt and rapid cycling were coded as present if observed at any moment of the course of the illness (lifetime presence). Substance misuse disorder was defined as the lifetime presence of abuse or dependence to alcohol, or cannabis or any other illicit drugs (except nicotine dependence).

\subsection{Dimensional assessment}

Childhood traumatic events were recorded using the Childhood Trauma Questionnaire (CTQ) that is a 28-item self-report questionnaire (Bernstein and Fink, 1998). The CTQ yields a total score and five subscores for emotional and physical neglect, as well as emotional, physical and sexual abuse. For this analysis we only used scores for abuse since we have suggested that more severe clinical outcome in BD seem to be mainly driven by abuse and rather than neglect (Etain et al., 2013a). All variables (three sub scores for abuse) were used as continuous variables measuring trauma severity.

The Affect Intensity Measure (AIM) comprises 40 items and defines affect intensity as responses to a given level of emotionprovoking stimulation. The total score is the mean of items scores. The original authors demonstrated the validity and the temporal stability of the AIM (Diener et al., 1985; Larsen et al., 1986, 1987). We used the French validated version (Mathieu et al., 2014).

Affective lability was measured using the Affective Lability Scale (ALS) (Harvey et al., 1989). The ALS includes 54 questions, rated on a four-point Likert scale ranging from 'very uncharacteristic of me' to 'very characteristic of me'. The responses are coded from 0 to 3 . The total score is the mean of all item responses divided by the number of responses, thus ranging from 0 to 3 . The main psychometric properties of the French version of the ALS have been previously reported (Aas et al., 2014b).

Impulsivity was assessed with the French version (Bayle et al., 2003; Caci et al., 2010) of the Barratt Impulsiveness Scale (BIS, version 10) (Patton et al., 1995), a 34-item self-report questionnaire that was developed for the measurement of impulsiveness as a stable characteristic. Each item is rated on a 4-point scale ranging from 1 (rarely/never) to 4 (almost always/always).

The Buss-Durkee Hostility Inventory (BDHI) is a 75 items questionnaire (Buss and Durkee, 1957) designed to measure individual differences in traits of general aggression and hostility. Each item is a false/true assertion. Two components were used as described by the validation article: Attitudinal (Resentment, Suspicion and Guilt) and Motor (Assault, Indirect Hostility, Verbal Hostility and Irritability) components of hostility. We used a French version of the BDHI (Consoli et al., 1993).

\subsection{Statistical analysis}

Descriptive statistics (Mean (SD), median, range and N (\%)) were used to examine the characteristics of the sample. Non-parametric tests were used to correlate continuous variables (Spearman rho test). Significance was evaluated based on a two-tailed test, we choose a critical value at $p<0.001$ given the number of paths investigated. All statistical analyses were implemented with Mplus 6.1 (Muth en and Muth en, 2007).

Path analyses from emotional, physical and sexual abuse to the dimensional measures (affect intensity, affective lability, impulsivity, attitudinal hostility and motor hostility) and the clinical variables were performed using WLSMV estimator (Weighted Least Squares Mean and Variance) to deal with categorical variables. The model examined both direct and indirect associations between these abuse subscales and the continuous and categorical outcomes. The model also estimated correlations amongst (i) the three abuse types, and (ii) the dimensional and categorical outcomes. A path diagram representation of the model was then drawn: straight single-headed arrows represented regression paths; the curved tow-headed arrow represented correlations.

An iterative procedure allowed the selection of the best-fitting model. The path analysis started with a saturated model in which all variables were interrelated. Then non-significant path correlations/associations were gradually excluded until a good-fitting model was reached. Goodness of fit was reported using standard indices: the Chi-square statistic, Comparative Fit Index (CFI), the Root Mean Square Error of Approximation (RMSEA). Rules of thumb for determining acceptable model fit were as follows: a nonsignificant Chi-square test, a CFI value of 0.90 or above, and RMSEA values close to 0.05 or below. All path coefficients and correlations are reported as standardized estimates.

\section{Results}

The sample consisted of 485 euthymic BD patients (203 men and 282 women) with a mean age at interview of $40.9( \pm 12.6)$ years old. The socio-demographic, clinical and dimensional description of the sample is presented in Table 1.

\subsection{Correlations between trauma subtypes and dimensions of psychopathology}

Table 2 provided the matrix of correlations between continuous variables. Most correlations were statistically significant except between physical abuse and affect intensity. The only correlation coefficient that exceeded 0.50 was between affect intensity and affective lability.

\subsection{Path analysis}

Indices of goodness of fit of the model were as followed: 
Table 1

Demographic, clinical and dimensional characteristics of the sample of patients with BD (n $1 / 4485)$.

\begin{tabular}{|c|c|c|c|c|c|c|}
\hline Variables & $\mathrm{N}$ & $\%$ & Mean & SD & Median & Range \\
\hline Gender (males) & 203 & $41.9 \%$ & & & & \\
\hline Type of BD (BD1) & 301 & $62.1 \%$ & & & & \\
\hline Suicide attempt (lifetime presence) & 172 & $35.4 \%$ & & & & \\
\hline Rapid cycling (lifetime presence) & 58 & $12 \%$ & & & & \\
\hline Subtance misuse (lifetime presence) & 137 & $28.3 \%$ & & & & \\
\hline Polarity at onset (depressive onset) & 334 & $69 \%$ & & & & \\
\hline Lifetime psychotic features & 220 & $45.4 \%$ & & & & \\
\hline Age at interview & & & 40.9 & 12.6 & 40 & $16 \mathrm{e} 86$ \\
\hline Age at onset & & & 24.5 & 9.6 & 22 & $7 e 66$ \\
\hline MADRS score & & & 4.81 & 4.1 & 0 & $0 \mathrm{e} 14$ \\
\hline YMRS score & & & 1.14 & 1.7 & 0 & $0 \mathrm{e} 7$ \\
\hline Impulsivity score (BIS) & & & 65.14 & 10.2 & 64 & $43 \mathrm{e} 101$ \\
\hline Affect Intensity score (AIM) & & & 3.56 & 0.7 & 3.53 & $1.6 \mathrm{e} 5.4$ \\
\hline Affective Lability score (ALS) & & & 1.1 & 0.6 & 1.1 & $0 \mathrm{e} 3$ \\
\hline Motor Hostility score (BDHI) & & & 20 & 7.5 & 20 & $2 \mathrm{e} 40$ \\
\hline Attitudinal Hostility score (BDHI) & & & 6.72 & 4.1 & 6 & $0 \mathrm{e} 17$ \\
\hline Emotional Abuse score & & & 9.77 & 4.9 & 8 & $5 e 25$ \\
\hline Sexual Abuse score & & & 6.34 & 3.3 & 5 & $5 e 25$ \\
\hline Physical Abuse score & & & 6.27 & 2.5 & 5 & $5 \mathrm{e} 20$ \\
\hline Emotional Neglect score & & & 11.48 & 4.8 & 11 & $5 e 25$ \\
\hline Physical Neglect score & & & 6.79 & 2.4 & 6 & $5 e 18$ \\
\hline CTQ total score & & & 40.63 & 13.15 & 38 & $25 \mathrm{e} 92$ \\
\hline
\end{tabular}

BD: Bipolar Disorder; N: number of patients, SD: Standard Deviation, MADRS: Montgomery Asberg Depression Rating Scale; YMRS: Young Mania rating Scale; BIS; Barrat Impulsivity Scale; ALS: Affective lability Scale: AIM: Affect Intensity Measure: BDHI: Buss Durkee Hostility Inventory.

Table 2

Correlation matrix between childhood abuse and dimensions scores.

\begin{tabular}{|c|c|c|c|c|c|c|c|c|}
\hline & & EA & SA & PA & BIS & ALS & AIM & BDHIMot \\
\hline SA & $\begin{array}{l}\text { rho } \\
p\end{array}$ & $\begin{array}{l}0.32 \\
<0.0001\end{array}$ & & & & & & \\
\hline PA & $\begin{array}{l}\text { rho } \\
p\end{array}$ & $\begin{array}{l}0.45 \\
<0.0001\end{array}$ & $\begin{array}{l}0.23 \\
<0.0001\end{array}$ & & & & & \\
\hline BIS & $\begin{array}{l}\text { rho } \\
p\end{array}$ & $\begin{array}{l}0.20 \\
<0.0001\end{array}$ & $\begin{array}{l}0.11 \\
0.0158\end{array}$ & $\begin{array}{l}0.15 \\
0.0009\end{array}$ & & & & \\
\hline ALS & $\begin{array}{l}\text { rho } \\
p\end{array}$ & $\begin{array}{l}0.27 \\
<0.0001\end{array}$ & $\begin{array}{l}0.13 \\
0.0046\end{array}$ & $\begin{array}{l}0.16 \\
0.0004\end{array}$ & $\begin{array}{l}0.41 \\
<0.0001\end{array}$ & & & \\
\hline AIM & $\begin{array}{l}\text { rho } \\
p\end{array}$ & $\begin{array}{l}0.20 \\
<0.0001\end{array}$ & $\begin{array}{l}0.14 \\
0.0016\end{array}$ & $\begin{array}{l}0.09 \\
0.058\end{array}$ & $\begin{array}{l}0.37 \\
<0.0001\end{array}$ & $\begin{array}{l}0.61 \\
<0.0001\end{array}$ & & \\
\hline BDHIMot & $\begin{array}{l}\text { rho } \\
p\end{array}$ & $\begin{array}{l}0.21 \\
<0.0001\end{array}$ & $\begin{array}{l}0.11 \\
0.018\end{array}$ & $\begin{array}{l}0.16 \\
0.0003\end{array}$ & $\begin{array}{l}0.33 \\
<0.0001\end{array}$ & $\begin{array}{l}0.48 \\
<0.0001\end{array}$ & $\begin{array}{l}0.48 \\
<0.0001\end{array}$ & \\
\hline BDHIAtt & $\begin{array}{l}\text { rho } \\
p\end{array}$ & $\begin{array}{l}0.41 \\
<0.0001\end{array}$ & $\begin{array}{l}0.17 \\
0.0001\end{array}$ & $\begin{array}{l}0.22 \\
<0.0001\end{array}$ & $\begin{array}{l}0.30 \\
<0.0001\end{array}$ & $\begin{array}{l}0.48 \\
<0.0001\end{array}$ & $\begin{array}{l}0.36 \\
<0.0001\end{array}$ & $\begin{array}{l}0.47 \\
<0.0001\end{array}$ \\
\hline
\end{tabular}

EA: emotional abuse, PA: physical abuse, SA: sexual abuse, BIS; Barrat Impulsivity Scale; ALS: Affective lability Scale: AIM: Affect Intensity Measure: BDHIMot: Buss Durkee Hostility Inventory Motor component; BDHIAtt: Buss Durkee Hostility Inventory Attitudinal component.

Rho: Spearman Coefficient; $p$ : $p$ value.

$c^{2} 1 / 451.48$ (df $1 / 4$ 44) p $1 / 40.204 ;$ CFI $1 / 40.99$ and RMSEA $1 / 40.02$. As shown on the left part of Fig. 1, correlation estimates between emotional, physical and sexual abuse were significant (0.27 rho $0.51 ; p<0.001)$. There were significant path coefficients for direct effects of emotional abuse on all psychopathological dimensions with standardized coefficients between 0.19 and $0.40(p<0.001)$. To a lesser extent, sexual abuse was associa with AIM ( $p$ 1/4 0.05) and BDHI Attitudinal component ( $p$ 1/4 0.004). No associations were observed between physical abuse and any of the psychological dimensions when taking into account emotional and sexual abuse in the model.

The right part of the path diagram showed significant associations between AIM $(p<0.001)$ and BDHI Attitudinal $(p<0.001)$ and suicide attempt. ALS ( $p$ 1/4 0.006) and BDHI Motor scores ( $p$ 1/4 0.02) also showed associations with suicide attempt but not significant after correction. BIS score was associated with substance misuse outcome $(p<0.001)$. The effects of BDHI Motor on both substance misuse $\left(p \frac{1}{4}\right.$ 0.009) and polarity at onset ( $p$ 1/4 0.05) were significant; but not after correction for multiple testing.

Some of the clinical outcomes were inter-related: suicide attempt and polarity at onset ( $\mathrm{p} 1 / 40.03$ ), rapid cycling and polarity at onset $(p 1 / 40.01)$, and substance misuse and age at onset AAO ( $p$ 1/4 0.05). No direct links were found between the childhood trauma sub-scores and the clinical variables.

Dimensions of psychopathology partially mediated the effect of emotional abuse on suicide attempt and substance misuse. The total direct effects were significant $(p<0.0001)$, as well as all the indirect effects (Emotional Abuse/AIM/Suicide Attempt $p$ 1/4 0.004; Emotional Abuse/ALS/Suicide Attempt $p$ 1/4 0.011; Emotional Abuse/ BHDI Attitudinal/Suicide Attempt $p<0.001$; Emotional abuse/BDHI Motor/Suicide Attempt $p$ 1/4 0.025; Emotional abuse/BIS/Substance Misuse $p 1 / 40.001$; Emotional abuse/BDHI Motor/Substance Misuse p $1 / 40.023$ ).

When adding Emotional and Physical Neglect in the model no 


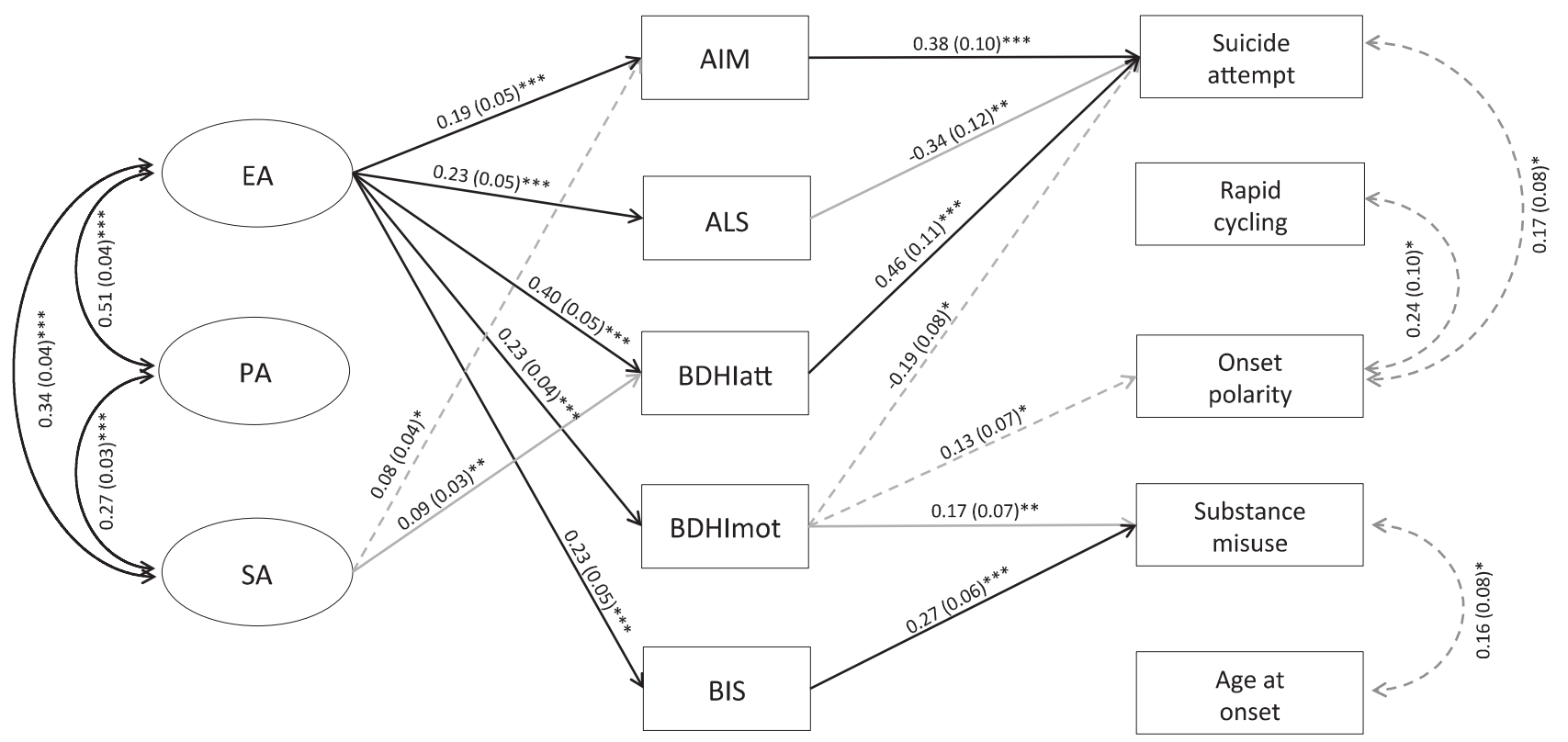

$\mathrm{N}=485$

Chisquare Test of Model fit $=51.48, \mathrm{df} 44 \mathrm{p}=0.204$

RMSEA (Root Mean square of Approximation): Estimate $=0.019, p=0.999$

$\mathrm{CFI} / \mathrm{TLI}: \quad \mathrm{CFI}=0.991$

$\mathrm{TLI}=0.984$

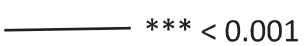

$* * 0.001-0.01$

$* 0.01-0.05$

Fig. 1. Path analysis diagram including three subtypes of childhood abuse, psychological dimensions and clinical outcomes in patients with BD.

Straight single-headed arrows represent regression paths and curved tow-headed arrows represent correlations.

All path coefficients and correlations are reported as standardized estimates.

The level of significance of number (correlation coefficients or regression coefficients) is given both by the type of arrow and the number of stars.

For reasons of clarity, the paths corresponding to $p$ values $>0.05$ were not included in the path diagram.

For reasons of clarity, the paths between AIM, ALS,BDHIAtt, BDHIMot and BIS are not displayed (all $p<0.001$ ).

EA: emotional abuse; PA: physical abuse; SA: sexual abuse.

AIM: Affect Intensity Measure; ALS: Affective Lability Scale; BDHIAtt: Buss Durkee Hostility Inventory Attitudinal component; BDHIMot: Buss Durkee Hostility Inventory Motor

component; BIS: Barrat Impulsivity Scale.

RMSEA: Root Mean Square Error of Approximation; CFI: Comparative Fit Index; TLI: Tucker and Lewis Index.

additional significant path was observed; with the exception of an association between Emotional Neglect and ALS ( $p$ 1/4 0.011). We identified no significant path concerning Physical Neglect.

Finally, we performed a series of logistic regressions to explore whether the paths observed in our model in relation with Suicide Attempt and Substance Misuse (see Fig. 1) were still significant when adjusting for age and gender. Age did not contribute to any of the observed associations, whereas sex did (data not shown). Therefore we performed two additional path analyses in males and females separately. Since the division of the sample by two (282 females, 203 males) might result in a loss of power in hypothesis testing, we built a simplified model using Emotional Abuse only, the five dimensions of psychopathology and only two clinical variables (Suicide Attempt and Substance Misuse). The significant paths observed in Fig. 1 for the whole sample were also observed in females only (Supplementary Fig. 1). In males, we identified only one significant path from Emotional Abuse to Substance Misuse through the measure of impulsivity (BIS), but no path converging to Suicide Attempt (Supplementary Figs. 1 and 2).

\section{Discussion}

In a sample of euthymic patients suffering from BD, we demonstrated that emotional abuse was associated with higher levels of emotional dysregulation and impulsivity/hostility. Sexual abuse was associated with higher levels of attitudinal hostility and affect intensity. No influence of physical abuse on any of the dimensions was observed when other subtypes of trauma were accounted for. In turn, dimensions of emotional instability (affect intensity and attitudinal hostility) were associated with lifetime presence of suicide attempt while dimensions of impulsivity (and to a lesser extent motor hostility) were associated with lifetime presence of substance misuse. As postulated by Maniglio, this path analysis demonstrated that some trauma subtypes (sexual abuse as proposed in his systematic review, but mainly emotional abuse in our study) were indirectly related to suicide attempts and substance misuse (Maniglio, 2013).

In the model we have tested, emotional abuse seems to be more relevant with regards to the investigated dimensions of psychopathology as compared to other types of trauma. Stabilization of affect is generally thought to occur in a developmental progression. It has been proposed that as children mature cognitively, socially, and morally, their observed reactions to environmental stimuli become more predictable and stable (Gerson et al., 1996). Longitudinal data on Dutch mono- and dizygotic twin pairs have been analyzed to decompose the stability of the CBCL-JBD (Child Behavior Check-List Juvenile Bipolar Disorder) phenotype (high levels of aggressive behavior, anxious/depressed behavior and attention problems) into genetic and environmental contributions (Boomsma et al., 2006). The influences of common environment appeared to decrease over time, particularly between ages 7 and 10 years. Putting together this result with the overall decrease in influence of shared environment from 7 to 12 years, it suggests the possibility of an important environmental factor during the 
formative years of CBCL-JBD onset that may not be present later on. During this critical period of development that is childhood, the occurrence of emotional abuse might lead to abnormal trajectories of maturation of emotional and impulsive regulatory processes. We cannot exclude that physical and sexual abuse might also be relevant with regards to other dimensions that were not studied here (such as psychosis proneness or cognitive functioning for example). For example we demonstrated an interaction between childhood abuse and cannabis misuse on delusion proneness in an independent sample of bipolar patients (Etain et al., 2016). Nevertheless, concerning emotional regulation and impulsivity/hostility, emotional abuse seems to play a prominent role when other subtypes of trauma were incorporated in the model.

Suicide attempt and substance misuse represented severe conditions that are frequently associated to $B D$ and increase morbidity and mortality risks (Hayes et al., 2015). The prevalence of attempted suicide in BD type II and BD type I are similar: $32.4 \%$ and $36.3 \%$, respectively (Novick et al., 2010) with a further increased risk for those patients with comorbid alcohol or other substances use disorders (Carra et al., 2014). In this path analysis, we replicated the results we obtained in an independent sample showing an association between impulsivity and alcohol, cannabis or other substances misuses (Etain et al., 2013b) thus suggesting that substance misuse comorbidity might be related to impulse dyscontrol and/or motor hostility. We also found associations between affect intensity, attitudinal hostility and suicide attempt, but not with impulsivity or motor hostility. These findings extend some previous results we obtained in an independent sample of patients with $B D$. Indeed, like others (Perroud et al., 2011), we observed no association between BIS score and suicidal attempts (Etain et al., 2013b) in BD while we observed that some components of hostility were associated with suicidal behavior (Parmentier et al., 2012). Also $\mathrm{BDHI}$ baseline score (but not BIS score) significantly predicted, among other clinical variables, the risk of suicide attempt in a sample of patients with $\mathrm{BD}$ who have been followed up to 2 years (Galfalvy et al., 2006).

Affect intensity refers to stable individual differences in response intensity to a given level of emotion-provoking stimulation (Larsen et al., 1986). Attitudinal hostility might also be part of the emotional regulation processes as proposed in the validation article which also referred to "emotional hostility" (items measuring Resentment, Suspicion and Guilt) (Buss and Durkee, 1957). This suggests that in patients with $B D$, suicide attempts might be more related to the inability to appropriately regulate emotional outputs than to tone down motor or cognitive components of impulsivity. It has been suggested that the experience of high levels of affect accompanied by the inability to control these affects are the essential components leading to the risk of suicidal behavior (Links et al., 2000). A meta-analysis of 70 studies has suggested that the relationship between trait impulsivity and suicidal behaviors was small (Anestis et al., 2014). In the longitudinal data from the 2000 Adult Psychiatric Morbidity Survey, impulsivity significantly predicted the presence of suicidal thoughts, but this effect became non-significant with mood instability included in the same model (Peters et al., 2015). Other authors suggested that impulsive responses to emotions uniquely and significantly related to self-harm, suicide ideation, and suicide attempts among patients with BD (Johnson et al., 2016), meaning that impulsive responses to emotion (emotion-triggered impulsivity) was more relevant than other forms (i.e. motor) of impulsivity. Therefore, the links between impulsivity, emotional deregulation and suicidal behaviors in $\mathrm{BD}$ would deserve more research (Watkins and Meyer, 2013) including a more nuanced approach to impulsivity in bipolar suicidality and a greater focus on emotion regulation.

Several limitations require to be discussed. Childhood trauma assessment was retrospective so not exempt from potential uncontrolled recall biases. Nevertheless, a previous study has shown that individuals with severe mental illness are able to reliably report in adulthood on experiences of abuse during childhood (Fisher et al., 2011), while another study demonstrated similar findings specifically in patients with BD (Shannon et al., 2016). Clinical description of BD was also retrospective but recorded using reliable structured clinical interviews. All substances were pooled in the same "substance misuse" category. Suicide attempts were only characterized by their lifetime presence and we did not further explore other relevant characteristics that could provide higher resolution of the suicide phenotype. We also restricted our analysis to childhood abuse in order to provide a more parsimonious model but childhood neglect might also be relevant to be studied. Nevertheless, this choice was mainly based on our previous results showing that abuse might be more relevant to BD complexity/ severity than neglect (Aas et al., 2013; Etain et al., 2013a). The CTQ does not provide some relevant information related to childhood trauma such as age at the time of exposure, chronicity of exposure, perpetrators ... For instance, it has been demonstrated that age at exposure modulated the impact of childhood traumatic experiences on the psychopathological profile and the functional outcome in early psychosis (Alameda et al., 2015, 2016). The impact of age at exposure and other relevant characteristics of childhood trauma should be further investigated by models that attempt to link childhood trauma, dimensions of psychopathology and the clinical expression of BD. Finally, the two path-analyses stratified on sex might identified specific paths; in particular those related to suicide attempt that were observed only in females. This might be due to a gender effect or to a reduction of the power of the analyses when dividing the sample by two. This would require further exploration.

Another limitation is due to the assumptions on which our model was based, meaning that the dimensions of psychopathology are mediators between childhood trauma and clinical features of BD. First, we assumed that childhood trauma increase the levels of some psychopathological dimensions. We cannot exclude the fact that a reverse causation is also possible. For instance, an emotionally unstable or impulsive child might be overexposed to emotional trauma and harsh discipline when caregivers fail to find appropriate way to cope. The design being cross sectional and based on a retrospective measure of trauma makes impossible to exclude this possibility. Longitudinal studies have demonstrated that childhood trauma predicted later externalizing and internalizing behaviors (Briggs-Gowan et al., 2012; Slopen et al., 2014). Moreover, Rijlaarsdam and colleagues have shown that parental hostility and harsh discipline appeared to contribute to children's externalizing problems, independent of prior levels of child problem behavior (Rijlaarsdam et al., 2014). Therefore, future studies should attempt to clarify the direction of these paths, although a reverse causation is not supported by these latter findings. Second, this model assumed that these dimensions are considered to be stable, being viewed as "personality traits or aspects of temperament" and being constructed early during development. In a prospective cohort study of 3e12-year-old children, externalizing behaviors have been found to show considerable longitudinal stability throughout the developmental years (Pihlakoski et al., 2006). The longitudinal study of Dutch mono- and dizygotic twin pairs also showed that the within-person correlations, or stabilitycoefficient correlations across time of the CBCL-JBD phenotype were 0.72 from 7 to 10 years, 0.66 from 7 to 12 years, and 0.77 from 10 to 12 years meaning a stability across ages (Boomsma et al., 2006). Third, we made the assumption that these dimensions pre-exist to the occurrence of the clinical outcomes (onset of the disorder and related clinical features). For example, a review 
concluded that mood swings/affective lability belong to a risk constellation of prodromes that exists prior to the development of BD (Leopold et al., 2012). In the same way, increased impulsivity probably preexists to the development of BD (Faedda et al., 2014) Fourth, the "stability assumption" implies that the dimensions would be relatively little changed by mood state or the course of the disorder. All these dimensions are probably trait components but also affective-state dependent. For example, ALS score increased with depressive symptoms (Aminoff et al., 2012). In order to minimize this, patients were assessed during euthymic states as showed by very low scores of depressive and manic symptoms, but a minor effect cannot be definitively excluded. Moreover, we found no associations between AIM score and the number of mood episodes or duration of illness, which may indicate that level of affect intensity is not directly modified by clinical symptoms per se (Mathieu et al., 2014). Finally, we used each dimension as a unidimensional construct, here again to provide a more parsimonious model, but the investigation of each scales' sub-components might add more comprehensive information as we proposed in an independent sample using some sub-components of the ALS (Aas et al., 2016b).

We have recently reviewed the physiological and molecular mechanisms that might lead from childhood trauma to clinical outcomes in BD through dimensions of psychopathology or cognitive deficits (Aas et al., 2016a). Childhood trauma might impact the structure and functioning of several brain regions (medial prefrontal cortex, hippocampus, amygdala, anterior cingulate cortex, caudate nuclei, corpus callosum), some of them being key structures for the production, processing and regulation of emotions while others behave as a inhibitory control network for behaviors (Elton et al., 2014). Dysconnectivity between some brain regions involved in emotional and behavioral regulation could be linked to childhood trauma (Grant et al., 2014; Souza-Queiroz et al., 2016). This is a central hypothesis when interpreting the impact of childhood trauma on emotion deregulation and impulsivity/hostility. In turn, these dimensions might induce maladaptive coping strategies or greater sensitivity to later stressors. Other mechanisms might involve the impact of early adversity on biological markers belonging to the immune, circadian, neuroplasticity or oxidative stress systems, although the links with emotional and behavioral outputs remain to be clarified (Aas et al., 2016a).

Several clinical implications should be highlighted. First, patients with BD and a more unstable or severe form of the disorder should be systematically screened for childhood trauma, in particular those patients with suicide attempt and/or substance use disorders. Second, several psychosocial interventions, that target childhood traumatic experiences and their consequences should be discussed as part of a personalized care plan. For example, this might include trauma-focused cognitive behavior therapy or eye movement desensitization and reprocessing (Ehring et al., 2014), even though their efficacy remains to be specifically demonstrated in BD (Moreno-Alcazar et al., 2017). Third, it might be relevant also to targeting some psychological mediators (impulsivity, emotional instability) in order to improve some of the deleterious outcomes in BD. Some psychotherapy might focus on emotional regulation, such as Schema Therapy for Emotional Dysregulation or mindfulnessbased cognitive therapy for BD that is suggested to increase emotion-regulation abilities (Dadomo et al., 2016; Deckersbach et al., 2012).

\section{Conclusion}

This study provides re finement of the links between emotional abuse, affective/impulsive dimensions and the clinical complexity/ severity of BD in terms of suicide attempts and substance misuse. In clinical practice, childhood trauma should be systematically assessed since early adversity may influence affective/impulsive dimensions observed during remission, which in turn might influence the complexity, severity and prognosis of the disease. Since the effects of trauma on some psychopathological conditions has been suggested to be possibly reversible (Read et al., 2005), future research about psychotherapeutic interventions that would target both history of early traumatic events and affective/impulsive regulation strategies, may help improving the overall prognosis of bipolar disorder.

\section{Acknowledgments}

This research was supported by Foundation FondaMental, Creteil, France and by the Investissements d'Avenir Programs managed by the ANR under references ANR-11-IDEX-0004-02 and ANR-10-COHO-10-01.

\section{Role of funding source}

None.

\section{Contributors}

BE and MLa initiated the study, performed the statistical analyses, interpreted the data and wrote the article.

$\mathrm{BE}, \mathrm{CH}, \mathrm{VA}, \mathrm{JMA}, \mathrm{FB}, \mathrm{TB}, \mathrm{PC}, \mathrm{SG}, \mathrm{JPK}, \mathrm{CP}$ included and assessed the patients.

$\mathrm{BE}$ and $\mathrm{CH}$ are the coordinators of the FACE-BD cohort.

MLe is the director of the Fondamental Foundation which set up the FACE-BD cohort.

All authors contributed to revise and comment the paper.

All author approved the submitted version of the article.

\section{Conflict of interest}

None. The authors declare that they have no competing financial interests, or other interests that might be perceived to influence the results and discussion reported in this paper.

\section{Appendix A. Supplementary data}

Supplementary data related to this article can be found at http:// dx.doi.org/10.1016/j.jpsychires.2017.07.013.

\section{References}

Aas, M., Aminoff, S.R., Vik Lagerberg, T., Etain, B., Agartz, I., Andreassen, O.A., Melle, I., 2014a. Affective lability in patients with bipolar disorders is associated with high levels of childhood trauma. Psychiatry Res. $218(1 \mathrm{e} 2), 252 \mathrm{e} 255$.

Aas, M., Etain, B., Bellivier, F., Henry, C., Lagerberg, T., Ringen, A., Agartz, I., Gard, S., Kahn, J.P.,Leboyer, M., Andreassen, O.A., Melle, I., 2013. Additive effects of childhood abuse and cannabis abuse on clinical expressions of bipolar disorders. Psychol. Med. 1e10.

Aas, M., Henry, C., Andreassen, O.A., Bellivier, F., Melle, I., Etain, B., 2016a. The role of childhood trauma in bipolar disorders. Int. J.Bipolar Disord. 4 (1), 2.

Aas, M., Henry, C., Bellivier, F., Lajnef, M., Gard, S., Kahn, J.P.,Lagerberg, T.V., Aminoff, S.R.,Bjella, T., Leboyer, M., Andreassen, O.A., Melle, I., Etain, B., 2016b. Affective lability mediates the association between childhood trauma and suicide attempts, mixed episodes and co-morbid anxiety disorders in bipolar disorders. Psychol. Med. 1e11.

Aas, M., Pedersen, G., Henry, C., Bjella, T., Bellivier, F., Leboyer, M., Kahn, J.P. Cohen, R.F.,Gard, S., Aminoff, S.R., Lagerberg, T.V., Andreassen, O.A., Melle, I., Etain, B., 2014b. Psychometric properties of the Affective Lability Scale (54 and 18-item version) in patients with bipolar disorder, first-degree relatives, and healthy controls. J.Affect Disord. 172C, 375e380.

Agnew-Blais, J., Danese, A., 2016. Childhood maltreatment and unfavourable clinical outcomes in bipolar disorder: a systematic review and meta-analysis. Lancet Psychiatry 3 (4), 342e349.

Alameda, L., Ferrari, C., Baumann, P.S., Gholam-Rezaee, M., Do, K.Q., Conus, P., 2015. 
Childhood sexual and physical abuse: age at exposure modulates impact on functional outcome in early psychosis patients. Psychol. Med. 45 (13) $2727 \mathrm{e} 2736$.

Alameda, L., Golay, P., Baumann, P.S., Ferrari, C.Do, K.Q., Conus,P., 2016. Age at the time of exposure to trauma modulates the psychopathological profile in patients with early psychosis. J. Clin. Psychiatry 77 (5), e612e618.

American Psychiatric Association, 1994. Diagnostic and Statistical Manual of Mental Disorders, fourth ed. Washington DC

Aminoff, S.R., Jensen, J., Lagerberg, T.V., Hellvin, T., Sundet, K., Andreassen, O.A. Melle, I., 2012. An association between affective lability and executive functioning in bipolar disorder. Psychiatry Res. 198 (1), 58e61.

Anand, A., Koller, D.L., Lawson, W.B., Gershon, E.S.,Nurnberger, J.I.,Bi, G.S.C.2015. Genetic and childhood trauma interaction effect on age of onset in bipolar disorder: an exploratory analysis. J.Affect Disord. 179, 1e5.

Anestis, M.D., Soberay, K.A., Gutierrez, P.M., Hernandez, T.D., Joiner, T.E., 2014. Reconsidering the link between impulsivity and suicidal behavior. Pers. Soc. Psychol. Rev. 18 (4), 366e386.

Bayle, F.J., Krebs, M.O., Martin, C., Bouvard, M.P., Wender, P., 2003. [French version of Wender Utah rating scale (WURS)]. Canadian journal of psychiatry. Rev. Can Psychiatr. 48 (2), 132.

Bernstein, D.P., Fink, L., 1998. Childhood Trauma Questionnaire: a Retrospective Self-report - Manual. The psychological Corporation - Harcourt Brace and Company, San Antonio.

Boomsma, D.I., Rebollo, I., Derks, E.M., van Beijsterveldt, T.C., Althoff, R.R., Rettew, D.C., Hudziak, J.J.2006. Longitudinal stability of the CBCL-juvenile bipolar disorder phenotype: a study in Dutch twins. Biol. Psychiatry 60 (9), 912e920.

Boudebesse, C., Lajnef, M., Geoffroy, P.A., Bellivier, F., Nieto, I., Gard, S., Olie, E., Azorin, J.M., Kahn, J.P., Bougerol, T., Passerieux, C., Aubin, V., Milhiet, V., Folkard, S., French Academic Centres of Expertise for Bipolar Disorders, C. Leboyer, M., Henry, C., Etain, B., 2013. Chronotypes of bipolar patients in remission: validation of the French version of the circadian type inventory in the FACE-BD sample. Chronobiology Int. 30 (8), 1042e1049.

Briggs-Gowan, M.J., Carter, A.S., Ford, J.D.,2012. Parsing the effects violence exposure in early childhood: modeling developmental pathways. J.Pediatr. Psychol. 37 (1), $11 \mathrm{e} 22$.

Buss, A.H., Durkee, A., 1957. An inventory for assessing different kinds of hostility. J. Consult. Psychol. 21 (4), 343e349.

Caci, H.M., Bouchez, J., Bayle, F.J.,2010. An aid for diagnosing attention-deficit/ hyperactivity disorder at adulthood: psychometric properties of the French versions of two Wender Utah Rating Scales (WURS-25 and WURS-K). Compr. Psychiatry 51 (3), 325e331.

Cakir, S., Tasdelen Durak, R., Ozyildirim, I., Ince, E., Sar, V., 2016. Childhood trauma and treatment outcome in bipolar disorder. J. Trauma Dissociation 17 (4), 397 e409.

Carra, G., Bartoli, F., Crocamo, C.,Brady, K.T., Clerici, M., 2014. Attempted suicide in people with co-occurring bipolar and substance use disorders: systematic review and meta-analysis. J.Affect Disord. 167, 125e135.

Consoli, S.M., Cordier, S., Ducimetiere, P., 1993. Validation of a personality questionnaire designed for defining sub-groups at risk for ischemic cardiopathy or cancer in the Gazel cohort. Revue d'epidemiologie de sante publique 41 (4), $315 \mathrm{e} 326$.

Dadomo, H., Grecucci, A., Giardini, I., Ugolini, E., Carmelita, A., Panzeri, M., 2016. Schema therapy for emotional dysregulation: theoretical implication and clinical applications. Front. Psychol. 7, 1987.

Daruy-Filho, L., Brietzke, E., Lafer, B., Grassi-Oliveira, R., 2011. Childhood maltreatment and clinical outcomes of bipolar disorder. Acta Psychiatr. Scand. 124 (6), $427 \mathrm{e} 434$.

Deckersbach, T., Holzel, B.K., Eisner, L.R., Stange, J.P., Peckham, A.D., Dougherty, D.D. Rauch, S.L., Lazar, S., Nierenberg, A.A., 2012. Mindfulness-based cognitive therapy for nonremitted patients with bipolar disorder. CNS Neurosci. Ther. 18 (2), $133 e 141$.

Diener, E., Larsen, R.J.,Levine, S., Emmons, R.A., 1985. Intensity and frequency: dimensions underlying positive and negative affect. J. Pers. Soc. Psychol. 48 (5), $1253 e 1265$.

Ehring, T., Welboren, R., Morina, N., Wicherts, J.M., Freitag, J., Emmelkamp, P.M., 2014. Meta-analysis of psychological treatments for posttraumatic stress disorder in adult survivors of childhood abuse. Clin. Psychol. Rev. 34 (8), 645e657.

Elton, A., Tripathi, S.P., Mletzko, T., Young, J., Cisler, J.M., James, G.A., Kilts, C.D., 2014 Childhood maltreatment is associated with a sex-dependent functional reorganization of a brain inhibitory control network. Hum. Brain Mapp. 35 (4), 1654 e1667.

Erten, E., Funda Uney, A., Saatcioglu, O., Ozdemir, A., Fistikci, N., Cakmak, D., 2014 Effects of childhood trauma and clinical features on determining quality of life in patients with bipolar I disorder. J.Affect Disord. 162, $107 \mathrm{e} 113$.

Etain, B., Aas, M., Andreassen, O., Lorentzen, S., Dieset, I., Gard, S., Kahn, J. Bellivier, F., Leboyer, M., Melle, I.,C.,H.,2013a. Childhood trauma is associated with severe clinical characteristics of bipolar disorders. J. Clin. Psychiatry 74 (10), $991 \mathrm{e} 998$

Etain, B., Henry, C., Bellivier, F., Mathieu, F., Leboyer, M., 2008. Beyond genetics: childhood affective trauma in bipolar disorder. Bipolar Disord. 10 (8), 867e876.

Etain, B., Lajnef, M., Bellivier, F., Henry, C., M'Bailara, K., Kahn, J.P.,Leboyer, M., Fisher, H.L., 2016. Revisiting the association between childhood trauma and psychosis in bipolar disorder: a quasi-dimensional path-analysis. J. Psychiatr. Res. 84, 73e79.
Etain, B., Lajnef, M., Bellivier, F., Henry, C., M'Bailara, K., Kahn, J.P.,Leboyer, M., Fisher, H.L., 2017. Revisiting the association between childhood trauma and psychosis in bipolar disorder: a quasi-dimensional path-analysis. J.psychiatric Res. 84, $73 \mathrm{e} 79$.

Etain, B., Mathieu, F., Liquet, S., Raust, A., Cochet, B., Richard, J.R., Gard, S., Zanouy, L., Kahn, J.P.,Cohen, R.F.,Bougerol, T., Henry, C., Leboyer, M., Bellivier, F., 2013b. Clinical features associated with trait-impulsiveness in euthymic bipolar disorder patients. J.Affect Disord. 144 (3), 240e247.

Faedda, G.L.,Serra, G., Marangoni, C., Salvatore, P., Sani, G., Vazquez,G.H., Tondo, L. Girardi, P.,Baldessarini, R.J.,Koukopoulos, A., 2014. Clinical risk factors for bipolar disorders: a systematic review of prospective studies. J. Affect Disord. 168, $314 \mathrm{e} 321$.

First, M., Sptzer, R., Gibbon, M., William, J., 1995. Structured Clinical Interview for DSM-IV Axis I DisordersdPatient Edition (SCID-I/P). New York State Psychiatric Institute, New York.

Fisher, H., Hosang, G., 2010. Childhood maltreatment and bipolar disorder: a critical review of the evidence. Mind Brain, J.Psychiatry 1e11.

Fisher, H.L., Craig, T.K., Fearon, P., Morgan, K., Dazzan, P.,Lappin, J.,Hutchinson, G., Doody, G.A., Jones, P.B., McGuffin, P., Murray, R.M., Leff, J., Morgan, C., 2011. Reliability and comparability of psychosis patients' retrospective reports of childhood abuse. Schizophr. Bull. 37 (3), 546e553.

Galfalvy, H., Oquendo, M.A., Carballo, J.J.,Sher, L., Grunebaum, M.F., Burke, A. Mann, J.J.,2006. Clinical predictors of suicidal acts after major depression in bipolar disorder: a prospective study. Bipolar Disord. 8 (5 Pt 2), 586e595.

Garno, J.L.,Gunawardane, N., Goldberg, J.F.,2008. Predictors of trait aggression in bipolar disorder. Bipolar Disord. 10 (2), 285e 292.

Gerson, A.C., Gerring, J.P., Freund, L., Joshi, P.T., Capozzoli, J., Brady, K., Denckla, M.B., 1996. The Children's Affective Lability Scale: a psychometric evaluation of reliability. Psychiatry Res. 65 (3), 189e198.

Godin, O., Etain, B., Henry, C., Bougerol, T., Courtet, P., Mayliss, L., Passerieux, C., Azorin, J.M., Kahn, J.P., Gard, S., Costagliola, D., Leboyer, M., FondaMental Advanced Centers of Expertise in Bipolar Disorders, C., 2014. Metabolic syndrome in a French cohort of patients with bipolar disorder: results from the FACE-BD cohort. J. Clin. Psychiatry 75 (10), 1078e1085 quiz 1085.

Grant, M.M., White, D., Hadley, J., Hutcheson, N., Shelton, R., Sreenivasan, K. Deshpande, G., 2014. Early life trauma and directional brain connectivity within major depression. Hum. Brain Mapp. 35 (9), 4815e4826.

Harvey, P.D., Greenberg, B.R., Serper, M.R., 1989. The affective lability scales: development, reliability, and validity. J.Clin. Psychol. 45 (5), $786 \mathrm{e} 793$.

Hayes, J.F., Miles, J., Walters, K., King, M., Osborn, D.P., 2015. A systematic review and meta-analysis of premature mortality in bipolar affective disorder. Acta Psychiatr. Scand. 131 (6), 417e425.

Henry, C., Etain, B., Mathieu, F., Raust, A., Vibert, J.F.,Scott, J., Leboyer, M., 2011 A French network of bipolar expert centres: a model to close the gap between evidence-based medicine and routine practice. J. Affect Disord. 131 (1e3), $358 \mathrm{e} 363$.

Henry, C., Van den Bulke, D., Bellivier, F., Roy, I., Swendsen, J., Siever, L.J., Leboyer, M. 2007. Affective lability and affect intensity as core diensions of bipolar disorders during euthymic period. Psychiatr. Res. 159 (1e2), 1 e6

Janiri, D., Sani, G., Danese, E., Simonetti, A., Ambrosi, E., Angeletti, G., Erbuto, D. Caltagirone, C., Girardi, P.,Spalletta, G., 2014. Childhood traumatic experiences of patients with bipolar disorder type I and type II. J. Affect Disord. 175C, 92e97.

Johnson, S.L., Carver, C.S., Tharp, J.A., 2016. Suicidality in bipolar disorder: the role of emotion-triggered impulsivity. Suicide Life Threat Behav. 47 (2), 177e192.

Larsen, R.J.,Diener, E., Cropanzano, R.S., 1987.Cognitive operations associated with individual differences in affect intensity. J.Pers. Soc. Psychol. 53 (4), 767e774.

Larsen, R.J., Diener, E., Emmons, R.A., 1986. Affect intensity and reactions to daily life events. J.Pers. Soc. Psychol. 51, 803 e814.

Leopold, K., Ritter, P., Correll, C.U., Marx, C., Ozgurdal, S., Juckel, G., Bauer, M. Pfennig, A., 2012. Risk constellations prior to the development of bipolar disorders: rationale of a new risk assessment tool. J. Affect Disord. 136 (3), $1000 \mathrm{e} 1010$.

Li, X.B., Liu, J.T.,Zhu, X.Z., Zhang, L., Tang, Y.L.,Wang, C.Y.,2014. Childhood trauma associates with clinical features of bipolar disorder in a sample of Chinese patients. J.Affect Disord. 168, 58e63.

Links, P.S.,Boggild, A., Sarin, N., 2000. Modeling the relationship between affective lability, impulsivity, and suicidal behavior in patients with borderline personality disorder. J.Psychiatr. Pract. 6 (5), 247e255

Maniglio, R., 2013. The impact of child sexual abuse on the course of bipolar disorder: a systematic review. Bipolar Disord. 15 (4), 341e358.

Marwaha, S., Gordon-Smith, K., Broome, M., Briley, P.M., Perry, A., Forty, L. Craddock, N., Jones, I., Jones, L., 2016. Affective instability, childhood trauma and major affective disorders. J.Affect Disord. 190, 764e771.

Mathieu, F., Etain, B., Daban, C., Raymond, R., Raust, A., Cochet, B., Gard, S. M'Bailara, K., Desage, A., Kahn, J.P., Wajsbrot-Elgrabli, O., Cohen, R.F. Azorin, J.M., Leboyer, M., Bellivier, F., Scott, J.,Henry, C., 2014. Affect intensity measure in bipolar disorders: a multidimensional approach. J. Affect Disord. $157,8 \mathrm{e} 13$

Montgomery, S.A., Asberg, M., 1979. A new depression scale designed to be sensitive to change. Br. J.Psychiatry 134, 382e389.

Moreno-Alcazar, A., Radua, J., Landin-Romero, R., Blanco, L., Madre, M., Reinares, M. Comes, M., Jimenez, E., Crespo, J.M., Vieta, E., Perez, V., Novo, P., Donate, M., Cortizo, R., Valiente-Gomez, A., Lupo, W., McKenna, P.J.,Pomarol-Clotet, E., Amann, B.L., 2017. Eye movement desensitization and reprocessing therapy versus supportive therapy in affective relapse prevention in bipolar patients 
with a history of trauma: study protocol for a randomized controlled trial. Trials 18 (1), 160.

Muth en, L., Muth en, B., 2007. MPLUS, (Version 6.11). Muth en \& Muth en, Los Angeles, CA.

Novick, D.M., Swartz, H.A., Frank, E., 2010. Suicide attempts in bipolar I and bipolar II disorder: a review and meta-analysis of the evidence. Bipolar Disord. 12 (1), 1 e9.

Olie, E., Seyller, M., Beziat, S., Loftus, J., Bellivier, F., Bougerol, T., Belzeaux, R., Azorin, J.M., Gard, S., Kahn, J.P.,Passerieux, C., Leboyer, M., Etain, B., Henry, C., Courtet, P., 2015. Clinical and neuropsychological characteristics of euthymic bipolar patients having a history of severe suicide attempt. Acta Psychiatr. Scand. 131 (2), 129e138.

Parmentier, C., Etain, B., Yon, L., Misson, H., Mathieu, F., Lajnef, M., Cochet, B., Raust, A., Kahn, J.P.,Wajsbrot-Elgrabli, O., Cohen, R., Henry, C., Leboyer, M., Bellivier, F., 2012. Clinical and dimensional characteristics of euthymic bipolar patients with or without suicidal behavior. Eur. Psychiatry : J. Assoc. Eur. Psychiatrists $27(8), \quad 570$ e576.

Patton, J.H., Stanford, M.S., Barratt, E.S., 1995. Factor structure of the Barratt impulsiveness scale. J. Clin. Psychol. 51 (6), 768 e774.

Pavlova, B., Perroud, N., Cordera, P.,Uher, R., Dayer, A., Aubry, J.M.,2016. Childhood maltreatment and comorbid anxiety in people with bipolar disorder. J. Affect Disord. 192, 22e27.

Perroud, N., Baud, P., Mouthon, D., Courtet, P., Malafosse, A., 2011. Impulsivity, aggression and suicidal behavior in unipolar and bipolar disorders. J. Affect Disord. 134 (1e3), 112e118.

Peters, E.M., Balbuena, L., Marwaha, S.,Baetz, M., Bowen, R., 2015. Mood instability and impulsivity as trait predictors of suicidal thoughts. Psychol. Psychother. 89 (4), $435 \mathrm{e} 444$.

Pihlakoski, L., Sourander, A., Aromaa, M., Rautava, P., Helenius, H., Sillanpaa, M., 2006. The continuity of psychopathology from early childhood to preadolescence: a prospective cohort study of 3-12-year-old children. Eur. Child. Adolesc. Psychiatry 15 (7), 409e417.

Post, R.M., Altshuler, L.L., Kupka, R., McElroy, S.L.,Frye, M.A., Rowe, M., Grunze, H., Suppes, T., Keck Jr., P.E., Leverich, G.S., Nolen, W.A., 2016. Age of onset of bipola disorder: combined effect of childhood adversity and familial loading of psychiatric disorders. J.Psychiatr. Res. 81, 63e70.

Post, R.M., Altshuler, L.L., Kupka, R., McElroy, S.L., Frye, M.A., Rowe, M., Leverich, G.S., Grunze, H., Suppes, T., Keck Jr., P.E., Nolen, W.A., 2014. Verbal abuse, like physical and sexual abuse, in childhood is associated with an earlier onset and more difficult course of bipolar disorder. Bipolar Disord. 17 (3), 323e330.

Post, R.M., Altshuler, L.L., Kupka, R., McElroy, S.L., Frye, M.A., Rowe, M., Leverich, G.S. Grunze, H., Suppes, T., Keck Jr., P.E., Nolen, W.A., 2015. Verbal abuse, like physical and sexual abuse, in childhood is associated with an earlier onset and more difficult course of bipolar disorder. Bipolar Disord. 17 (3), 323e330.

Read, J., van Os, J., Morrison, A.P., Ross, C.A., 2005. Childhood trauma, psychosis and schizophrenia: a literature review with theoretical and clinical implications. Acta Psychiatr. Scand. 112 (5), 330e350.

Rijlaarsdam, J., Stevens, G.W., Jansen, P.W., Ringoot, A.P., Jaddoe, V.W., Hofman, A., Ayer, L., Verhulst, F.C., Hudziak, J.J.,Tiemeier, H., 2014. Maternal childhood maltreatment and offspring emotional and behavioral problems: maternal and paternal mechanisms of risk transmission. Child. maltreatment $19(2), \quad 67 \mathrm{e} 78$.

Shannon, C., Hanna, D., Tumelty, L., Waldron, D., Maguire, C., Mowlds, W., Meenagh, C., Mulholland, C., 2016. Reliability of reports of childhood trauma in bipolar disorder: a test-retest study over eighteen months. J. Trauma Dissociation 17 (4), 511e519.

Slopen, N., Koenen, K.C., Kubzansky, L.D., 2014. Cumulative adversity in childhood and emergent risk factors for long-term health. J. Pediatr. 164 (3), e631e632, 631-638.

Souza-Queiroz, J., Boisgontier, J., Etain, B., Poupon, C., Duclap, D., d'Albis, M.A., Daban, C., Hamdani, N., Le Corvoisier, P., Delavest, M., Bellivier, F., Guevara, P., Leboyer, M., Henry, C., Houenou, J., 2016. Childhood trauma and the limbic network: a multimodal MRI study in patients wsith bipolar disorder and controls. J.Affect Disord. 200, $159 \mathrm{e} 164$.

Upthegrove, R., Chard, C., Jones, L., Gordon-Smith, K., Forty, L., Jones, I., Craddock, N., 2015. Adverse childhood events and psychosis in bipolar affective disorder. Br. J. Psychiatry 206 (3), 191e197.

Watkins, H.B., Meyer, T.D., 2013. Is there an empirical link between impulsivity and suicidality in bipolar disorders? A review of the current literature and the potential psychological implications of the relationship. Bipolar Disord. $15(5)$ $542 \mathrm{e} 558$.

Watson, S., Gallagher, P., Dougall, D., Porter, R., Moncrieff, J., Ferrier, I.N., Young, A.H., 2013. Childhood trauma in bipolar disorder. Aust. N. Z. J. psychiatry 48 (6), $564 \mathrm{e} 570$.

Young, R.C., Biggs, J.T.,Ziegler, V.E., Meyer, D.A., 1978. A rating scale for mania: reliability, validity and sensitivity. Br. J.Psychiatry 133, $429 \mathrm{e} 435$. 